\title{
MOLEULAR CHARACTERIZATION OF MYCOBACTERIAL ISOLATED FROM HUMAN AND ANIMALS
}

\author{
Soliman, Y.A. ${ }^{\mathbf{1}}$; Manal, El-Hamshary ${ }^{2}$; Rasmy, $\mathbf{M}^{\mathbf{1}}$. \\ ${ }^{1}$ Central Laboratory for Evaluation of Veterinary Biologics, Abbasia, Cairo. \\ ${ }^{2}$ Sadat university
}

\begin{abstract}
Sputum from clinically confirmed patient and lung tissues from tuberculin positive cattle were taken from el Menia governorate. The samples were subjected to mycobacterial isolation on Lowenstein Jensen media. Human samples gave 8 out of 20 positive culture with isolation rate of $40 \%$ where animal samples gave 11 out 15 positive culture with isolation rate of $73.3 \%$. Biochemical identification revealed that all the human isolates belonging to $\mathrm{M}$. tuberculosis where animal isolates where exclusively M. bovis. Molecular characterization using PCR utilizing primers set amplifying IS6110 gene revealed that all human and animal isolated were positive giving amplicon with relative molecular size of 254bp. When using primer set for detecting of the RD8 region, only human isolates gave a clear amplicon migrating about 673 bp which confirms that these isolates were belonging to M. tuberculosis.
\end{abstract}

Keywords:M. bovis; M. tuberculosis; RD8; IS6110 ; mycobacteria isolation

\section{INTRODUCTION}

Mycobacteria can infect and harbor a wide range of living hosts including both worm and cold blooded livings. Due to the close contact between animals and human especially in Upper Egypt, we have investigated the distribution of both $\mathrm{M}$. bovis and M. tuberculosis public health.

Bovine tuberculosis is caused by intracellular infection with the acid-fast bacterium, Mycobacterium bovis. In cattle, exposure to this organism can result in a chronic disease that jeopardises animal welfare and productivity, and in some countries leads to significant economic losses (Pollock and Neill, 2002). When disease develops, the associated granulomatous pathological changes are seen mainly in the lower and upper respiratory tract (Neill et al., 1994) and, because of this pattern, it is considered that infection most often follows aerosol exposure to M. bovis (Neill et al., 2001). Infected cattle are an important source of infection for other cattle and even human especially if they under stress or immunecompromised (Phillips et al., 2003).

M. bovis is a member of the tuberculosis complex of organisms and represents a serious zoonotic risk to Because of these ongoing economic and public health concerns, there is an urgent need for improved methods to combat bovine tuberculosis. Knowledge of bovine immune responses to $\mathrm{M}$. bovis can be utilised to develop new methods for disease diagnosis. Bovine tuberculosis infection in cattle is usually diagnosed in the live animal on the basis of delayed hypersensitivity reactions. Delayed hypersensitivity test is the standard method for detection of bovine tuberculosis. The comparative intradermal tuberculin test with bovine and avian tuberculin is used mainly to differentiate between animals infected with $\boldsymbol{M}$. bovis and those sensitized to tuberculin due to exposure to other mycobacteria (environmental) or related genera. This sensitizationcan be attributed to the antigenic cross-reactivity among mycobacterial species and related genera.

This study was undertaken for isolation, identification and molecular characterization of Mycobacteria from human and animal cases in Menia governorate.

\section{MATERIAL and METHODS Mycobacteriaisolation andidentification: Animal samples:}


Lungs showing $\mathrm{P} / \mathrm{M}$ lesions from tuberculin positive cross breed dairy cattle $(n=15)$ were collected from Menia Governorate. The samples were spliced of into small sections $3 \mathrm{~mm}$ thick and transferred to a sterile mortar containing washed sterile sand. Two $\mathrm{ml}$ of sterile distilled water were added to the crushed tissue, homogenized and ground till suspension was obtained. Two $\mathrm{ml}$ of $4 \%$ $\mathrm{H}_{2} \mathrm{So}_{4}$ acid were added to the mixture, and then incubated at $37^{\circ} \mathrm{C}$ for 30 minutes. The mixture was diluted with $16 \mathrm{ml}$ of sterile distilled water and centrifuged at 3000rpm for 20 minutes. The supernatant fluid was poured off into disinfectant $(5 \%$ phenol solution) and the obtained sediment was inoculated into two pyruvated Lowenstein Jensen slants. Then incubated at $37{ }^{\circ} \mathrm{C}$ in inclined position for overnight, then vertically for at least 6-8 weeks and examined daily over a week period then once a week. The obtained growths were observed for morphological character and for pigment production. those gave acid fast bacilli were further cultured in Middlebrook 7H9 liquid medium supplemented with albumin dextrose-catalase enrichment (Difco,) at $37^{\circ} \mathrm{Cfor} 4-6$ weeks.

\section{Human samples:}

Isolation of mycobacteria from human samples was done according to Kent and Kubica1985 following the method of Petroff et al., 1915 with modification according to Tripathi et al., 2014

Sputum samples $(3-5 \mathrm{ml})$ from clinically confirmed cases of pulmonary tuberculosis through $\mathrm{X}$ ray radiography $(n=$ 20) were taken in Menia governorate. Samples were homogenized for $15 \mathrm{~min}$ in a shaker using an equal volume of $4 \% \mathrm{NaOH}$ containing $05 \%$ NALC decontamination solution at room temp. After centrifugation at 3,000 rpm for $15 \mathrm{~min}$, the deposit was neutralized with $20 \mathrm{ml}$ of sterile distilled water. The samples were again centrifuged at $3000 \mathrm{rpm}$ for $15 \mathrm{~min}$. From the sediment, LJ medium was inoculated and smear was made. The culture slants were incubated in inclined position for overnight, then vertically at $37^{\circ} \mathrm{C} / 6$ month with daily observation. Colonies appears on slants were further sub-cultured on Middlebrook 7H9 liquid medium supplemented with albumin dextrose-catalase enrichment (Difco,) at $37^{\circ} \mathrm{Cfor} 4-6$ weeks.

\section{Biochemical identification:}

The growing animal and human isolates were subjected to morphological and biochemical identification using nitrate reduction test, niacin production test, Pyrazinamidase test, and growth on L.J. slants with either sodium Pyruvate or glycerol according to Kubica, 1973; and WHO, 1998.

\section{Polymerase chain reaction:}

Extraction of genomic DNA from field isolates:

According to Sambrook et al. (1989), and soliman et al., 2004

One hundred $\mathrm{mg}$ (wet weight) of the cell pellet of each isolate was resuspended in $0.5 \mathrm{ml}$ TE buffer, allowed for 2 cycles freezing and thawing. The cells were then homogenized in glass homogenizer, and then incubated 4 hours at $37^{\circ} \mathrm{C}$ with $5 \mathrm{ul}$ lysozymes (final concentration $100 \mu \mathrm{g} / \mathrm{ml}$ ). Proteinase-K was added $25 \mu \mathrm{l} / 0.5 \mathrm{ml}$ (final concentration $100 \mu \mathrm{g} / \mathrm{ml}$ ) and incubated for further 3 hours at $56^{\circ} \mathrm{C}$ with shaking. DNA was then extracted using Trizol reagent according to the manufacture instruction. Briefly, one milliliter Trizol was added and after 5 minutes of incubation at room temperature (RT), $0.4 \mathrm{ml}$ of chloroform was added, vortex for 15 seconds, kept at RT for 3 minutes. Then centrifuged at 14,000 $\mathrm{rpm} / 10 \mathrm{~min}$ at $4^{\circ} \mathrm{C}$. The upper aqueous phase containing RNA was completely discarded and the DNA in the interphase was precipitated with $0.6 \mathrm{ml}$ absolute ethanol and kept at RT for 3 minutes before centrifugation at $4000 \mathrm{rpm} / 5$ minutes at $4^{\circ} \mathrm{C}$. The supernatant was completely discarded and the DNA pellet was washed twice with 0.1 sodium citrate in $10 \%$ ethanol. At each time, the DNA pellet was kept in the washing solution for 30 minutes at RT with periodical mixing and centrifuged at $4000 \mathrm{rpm} / 5$ 
minutes at $4^{\circ} \mathrm{C}$. Following the 2 washes, the DNA was resuspended in $2 \mathrm{ml}$ of $75 \%$ ethanol, kept at RT for 20 minutes with periodical mixing and then centrifuged. The DNA pellet was finally dried briefly for 5 minutes under vacuum and redissolved in 50ul of $8 \mathrm{mM} \mathrm{NaOH}$. The $\mathrm{pH}$ was then adjusted at 8 by adding $115 \mu \mathrm{l} / \mathrm{ml}$ of $0.1 \mathrm{M}$ HEPES. Ten $\mu \mathrm{l}$ of RNAase were then added and incubated at $37^{\circ} \mathrm{C}$ for 1 hour then stored at $-20^{\circ} \mathrm{C}$ till used. The concentration and purity was measured using Nanodrop ND8000 Spectrophotometer (NanoDrop Technologies).

\section{RD8 gene:}

PCR amplification of IS6110 and

Both human and animal isolated were identified using primers that target both IS6110 that identify any typical mycobacterial isolates and the $R D 8$ gene that identify only the human isolated ( Mycobacterium tuberculosis ). The genomic DNA (50ng) was mixed with $10 \mu$ of dream tag master mix , 10 Q- solution and $100 \mathrm{nM}$ of either primer A or B ( table 1) ..The mixture was placed in the thermal cycler (T3000 professional, Biometra Inc, Germany), and adjusted at $95^{\circ} \mathrm{C} / 3 \mathrm{~min}$ for Initial denaturing then 40 cycles of denaturing at $95^{\circ} \mathrm{C} / 1 \mathrm{~min}$, annealing at 56 ${ }^{\circ} \mathrm{C} / 45$ seconds and extension at $72^{\circ} \mathrm{C} / 1 \mathrm{~min}$. A final extension step at $72^{\circ} \mathrm{C} / 10$ minutes was included. The product was then visualized by agarose gel electrophoresis. The product size was analysed using syngene software with 100bp DNA ladder as a marker (Sambrook et al. 1989 and Soliman et al., 2004)

\begin{tabular}{|c|c|c|c|c|c|}
\hline $\begin{array}{c}\text { gen } \\
\text { e }\end{array}$ & $\begin{array}{c}\text { Primer } \\
\text { name }\end{array}$ & sequence & $\begin{array}{l}\text { Product } \\
\text { length }\end{array}$ & $\begin{array}{l}\text { Strain to be } \\
\text { amplified }\end{array}$ & ref \\
\hline \multirow{2}{*}{$\begin{array}{l}0 \\
\vdots \\
\mathscr{0} \\
\mathscr{E}\end{array}$} & $\begin{array}{l}\text { INS- } \\
6110-\mathrm{F}\end{array}$ & CGTGAGGGCATCGAGGTGGC & \multirow[b]{2}{*}{$254 \mathrm{bp}$} & \multirow{2}{*}{$\begin{array}{l}\text { M. } \\
\text { tuberculosis } \\
\text { and } M . \text { bovis }\end{array}$} & \multirow{2}{*}{$\begin{array}{c}\text { Mehdik } \\
\text { hani } \\
\text { and } \\
\text { Rokni } \\
2012\end{array}$} \\
\hline & $\begin{array}{l}\text { INS- } \\
6110-\mathrm{R}\end{array}$ & GCGTAGGCGTCGGTGACAAA & & & \\
\hline \multirow{2}{*}{$\stackrel{\infty}{\hat{\imath}}$} & RD8-F & GGTGTGATTTGGTGAGACGATG & \multirow{2}{*}{$678 \mathrm{bp}$} & \multirow{2}{*}{$\begin{array}{l}M . \\
\text { tuberculosis }\end{array}$} & \multirow{2}{*}{$\begin{array}{c}\text { Stephen } \\
\text { et al., } \\
1999\end{array}$} \\
\hline & RD8-R & $\begin{array}{c}\text { AGTTCCTCCTGACTAATCCAGG } \\
\text { C }\end{array}$ & & & \\
\hline
\end{tabular}

Table (1) the primer sequence and the expected product size for the IS6110 and RD8 genes used in the current studRESULTS

Isolation and identification of animal isolatesAs seen in Fig (1), out of 15 specimens taken from the slaughtered tuberculin positive cattle, $11(73.3 \%)$ mycobacterium isolates were obtained on Lowenstein -Jensen media the biochemical identification revealed that all isolates were M. bovis. (Table 2)

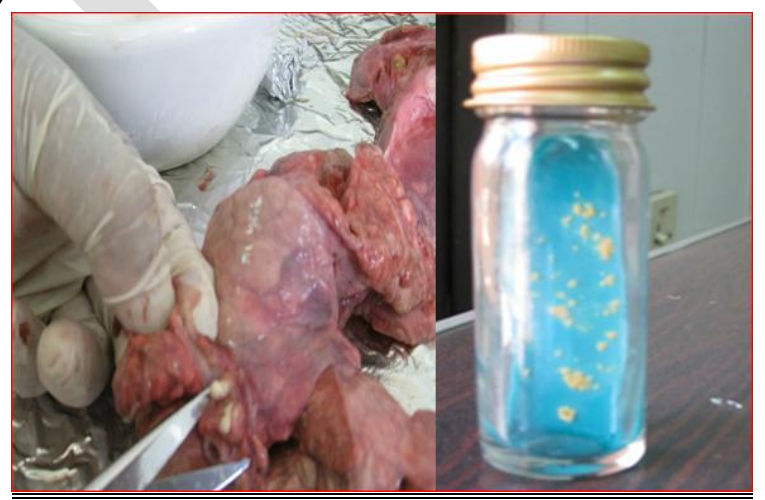

Fig (1) Lung show suspected tuberculous lesion (left) and L.J. media showing the growth of $M$. bovis after 2 months of incubation (right). 
Isolation and identification of human isolates.

Samples from patients confirmed to be infected with tuberculosis through X-ray examination of the chest were subjected to isolation of $\boldsymbol{M}$. tuberculosis. Out of 20 samples used in this study, 8 samples ( 40 $\%$ ) yield positive colonies on L.J. media by the week 8 these colonies were very few and tiny in appearance. After about 12 weeks nearly all the 8 samples gave clear colonies which appear as crumbly, "breadcrumb "rough", waxy, non-pigmented (buff colored). All isolates confirmed to be M. tuberculosis using biochemical identification (Table 2)

\section{Results of PCR:}

Two sets of PCR primers were used to detect and differentiate between $\boldsymbol{M}$. bovis and M. tuberculosis. All the 11 animal and 8 human isolates were tested with IS 6110 that detect all Mycobacteria and then tested with RD8 primers sets that detect only $\boldsymbol{M}$. tuberculosis. As seen in photo 3 and 4, all isolates were positive on using the IS 6110 primers, Indicating that all the isolates are Mycobacteria in nature. On testing the isolates with the primer sets that detect the RD8 region however, only the human isolates gave a positive amplicons migrating about 650bp which corresponding to $M$. tuberculosis 
Table (2): Results of physical and biochemical identification of the isolated acid fast bacilli from suspected human and animal samples.

\begin{tabular}{|l||l||l||}
\hline Test or property & M. bovis & M. tuberculosis \\
\hline \hline Number of isolates & 11 & 8 \\
\hline \hline Ziehl - Neelsen stain & Acid fast bacilli & Acid fast bacilli \\
\hline Growth at $28^{\circ} \mathrm{C}$ & - & - \\
\hline Growth at $37^{\circ} \mathrm{C}$ & + & + \\
\hline Growth at $42^{\circ} \mathrm{C}$ & \pm & \pm \\
\hline Colony morphology & Smooth & Rough \\
\hline Dark pigmentation & Non pigmented & Non pigmented \\
\hline Photo pigmentation & Non pigmented & Non pigmented \\
\hline Niacin production & - & + \\
\hline Nitrate reduction & - & - \\
\hline $\begin{array}{l}\text { Tween } 80 \quad \text { hydrolysis } \\
10 \text { days }\end{array}$ & - \\
\hline $\begin{array}{l}\text { Catalase semiquantitative } \\
<45\end{array}$ & - \\
\hline Catalase PH 7.0-68c0 & - & - \\
\hline Arylsulfatase $(3$ days $)$ & - & - \\
\hline Arylsulfatase $(2$ weeks $)$ & - \\
\hline Urease & + \\
\hline Iron uptake & - \\
\hline $\begin{array}{l}\text { Growth on TCH } \\
\text { Gg/ml) }\end{array}$ & - \\
\hline Growth on NaCl 5\% & - \\
\hline
\end{tabular}




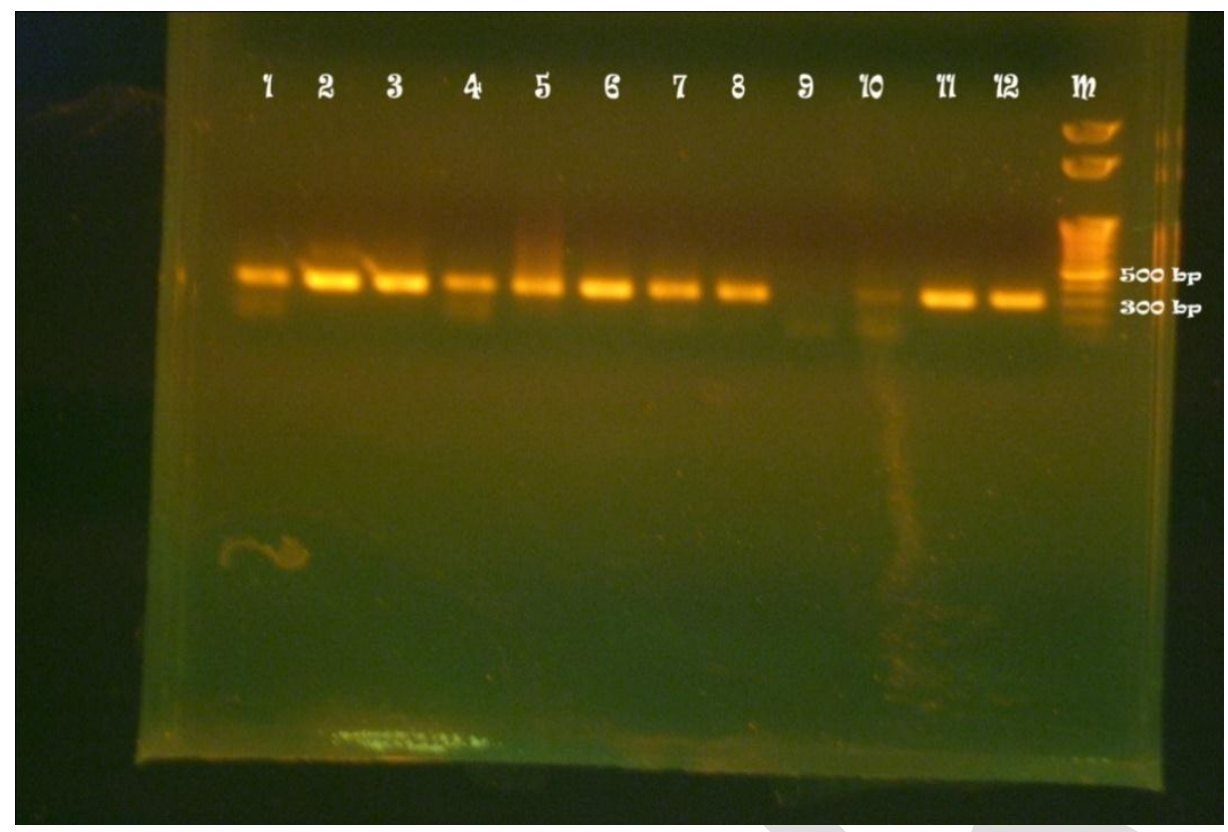

Photo (3) PCR amplification of the IS6110 of the animal isolates. Note that all the samples gave a positive amplicon migrating at about 250 bp except sample \#9 which serves as NTC (animal samples).

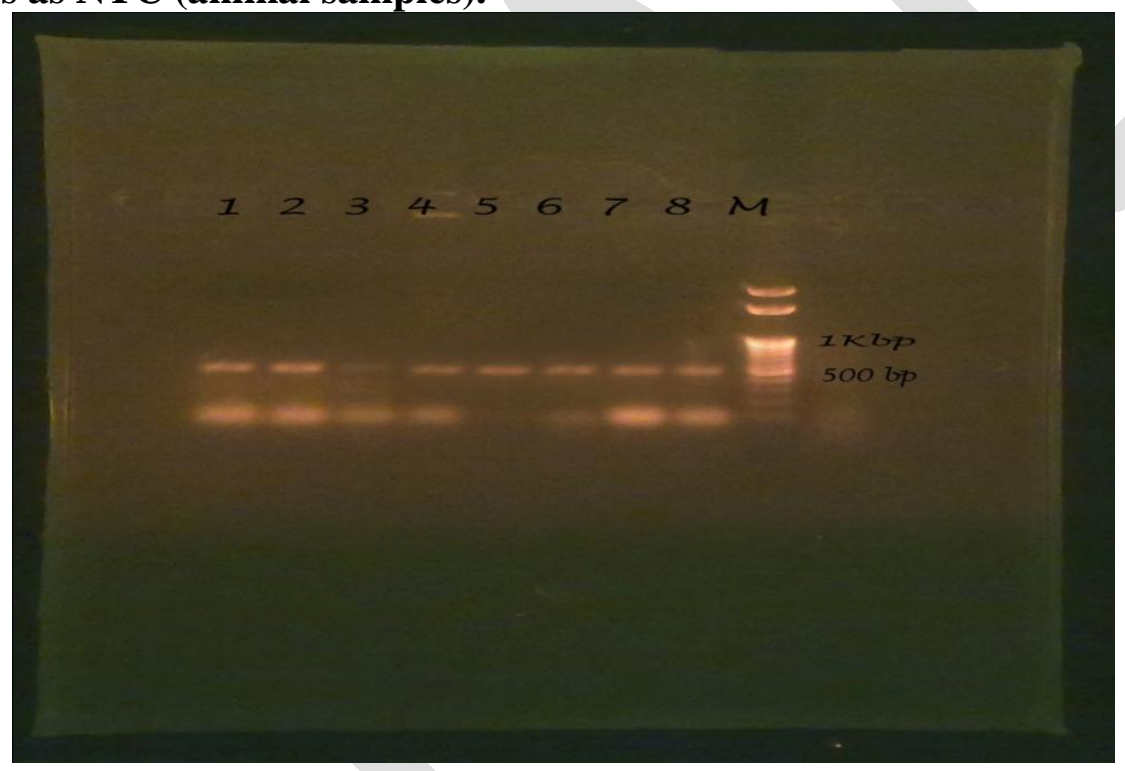

Photo (4) PCR amplification of a region in the RD8 which is absent in M. bovis relative to $M$. tuberculosis (human samples)

\section{DISCUSSION}

Tuberculosis infection in man and animals remains one of the most devastating disease with high morbidity and mortalities with subsequent sever economical impacts especially in the developing countries like Egypt, which requires maintained focusing on the behavior of the disease within the subjects and establishment a strict control measures.

$$
\text { Isolation of Mycobacterium }
$$
tuberculosis from biological samples is essential in molecular study, drug resistance survey and initiating treatment for cases suspected to developed drug resistance (Philip et al., 2012).

The total isolation rates of Mycobacteria from carcasses of reactors (tuberculin positive cattle) with lesions were summarized up in table (2). From a total of 15 cases 11 , positive cultures were recovered with an isolation rate of $73.3 \%$. Other investigators reported, however, lower rates (Gallo et al., 1983, 29.1\%, 
Payeur and Marquardt, 1988, 8.9\%). On the other hand, Chul Soon Choi (1981) in Korea reported a much higher isolation rate amounting to $92.1 \%$. These results depend mainly on the actual disease status present in the tested herd and to some extend on the experience of the investigators as well as the technique used for decontamination of tissue specimens.

In human cases, the isolation rate was much lower ( 8 out of 20 with a rate of 40 $\%)$ this lowered rate may attributed to the drug treatment in patients under investigation. one of the most critical factors that cases failure in Mycobacteria isolation from sputum, is the lower volume of the sample and the presence of large amount of commensalle and other pathogens in the immune-compromised patients (Anargyros et al., 1990).

The resurgence of tuberculosis in man and animals around the world especially in developing countries has renewed interest in understanding the epidemiology and pathogenesis of this disease. One important advance of molecular techniques is that itallows the identification and tracking of individual strains of Mycobacteria with very clear molecular probes. This new discipline, the molecular epidemiology, immerged with the identification of IS6110, a novel mycobacterial insertion sequence which formed the basis of a reproducible genotyping technique for $\boldsymbol{M}$. tuberculosis complex. Although other typing methods, appear to offer certain advantages in terms of reproducibility, economic cost, ease of execution and general applicability to clinical standards, IS6110-based typing remains the internationally accepted standard (Burgos and Pym,2002 ) and continues to provide new insights into the epidemiology of $\boldsymbol{M}$. tuberculosis. In the current study all the isolated strains both from human and animal hosts gave positive bands at the expected molecular size indication that these isolates were belonging to the $\mathrm{M}$ tuberculosis complex.

In order to differentiate between the human (M. tuberculosis) and animal isolates (M. bovis) a primer set was used that detect a conserved region in RD8 of $\boldsymbol{M}$. tuberculosis that is completely absent in $\boldsymbol{M}$. bovis. RD8 encompasses a region of 5895 bp on genome of the M. tuberculosis. The deletion contains six ORFs with a seventh, lpqQ, which codes for a truncated antigen termed lipoprotein, (truncated at the 5' end by deletion)

Among these six ORFs, Rv3619c and Rv3620c code for members of the ESAT-6 and QILSS families (Harboe et al., 1996 and Cole et al., 1998), and two encode PE and PPE proteins antigens that is used by Mycobacteria for energy transfer. The last two ORFs, ephA and Rv3618, code for a putative epoxide hydrolase and a possible mono-oxygenase protein antigens respectively.

\section{REFERENCES}

Anargyros, P.; David, S. J. and Irene S. L. 1990 Comparison of Improved BACTEC and Lowenstein-Jensen Media for Culture of Mycobacteria from Clinical SpecimensJ. clinical Micrbiol., 28(6): 12881291

Burgos, M.V. and . Pym, A.S. 2002Molecular epidemiology of tuberculosisEur Respir J; 20: Suppl. 36: 5465

Chul Soon Choi (1981):Mycobacterium isolated from man, animals and soil in Korea, 1968-1980 : a review .Korea J . Vet . Publ. Health , 5(1):49-64

Cole, S. T.; Brosch, R.; Parkhill, J. ;Garnier, T.; Churcher, ;C.; Harris S. V, et al., 1998.Deciphering the biology of Mycobacterium tuberculosis from the complete genome sequence.

Nature 393:537-544.

Gallo , J . A. G ; Veitia , F ; Remon, S. and Delgado , L 1983.Mycobacteria isolated from cattle reacting to tuberculin tests .Rev. cubana de ciencias veterinarias , 14(3) : 173-176

Harboe, M.;Oettinger, T.; Wiker, H.G.; Rosenkrands, I.; and Andersen, P. 1996Evidence for occurrence of the ESAT6 protein in Mycobacterium tuberculosis 
and virulent Mycobacterium bovis and for its absence in Mycobacterium bovis BCG. Infect Immun 64: 16-22.

Kent, P.T. and G.P. Kubica, 1985. Public Health Mycobacteriology: A Guide for the Level III Laboratory. U. S. Department of Health and Human Services, Centers for Disease Control: Atlanta.

Kubica, G.F. (1973):Differential identification of mycobacteria. VII. Key features for identification of clinically significant mycobacteria. Am. Rev. Resp. Dis., 107: 9-12.

Mehdikhani, S.H. and Rokni, N. 2012.Use of PCR Method Based on IS6110 for Detection of Mycobacterium tuberculosis Complex in CattleWorld Applied Sciences Journal 19 (4): 504-509.

Neill, S.D.; Bryson, D.G.and Pollock, J.M. 2001.Pathogenesis of tuberculosis in cattle. Tuberculosis 81, 79-86.

Neill, S. D.; Pollock, J. M.; Bryson, D. B. and Hanna, J. 1994.Pathogenesis of Mycobacterium bovis infection in cattle. Vet. Microbiol. 40:4152.

Payeur , J.B. and Marguardt , J. G. (1988):Mycobacterial isolates from submissions (National Vet. Services la boratories "NVSL" during FY (88- 87) processing in the united states anim. Health . assoc. 92 : 457- 477.

Petroff, S.A. 1915. A new and rapid method for the isolation and cultivation of the tubercle bacillus directly from sputum and feces. J. Exp. Med. 21(1):38-42.

Philip, R. A. ; Sanjay, M K. ; Sharma,z
Phillips, C.J.C.; Foster, C.R.W.; Morris, P.A.and Teverson, R. 2003.The transmission of Mycobacterium bovis infection to cattle.Res. Vet. Sci. 74, 1-15.

Pollock, J. M., and S. D. Neill. 2002. Mycobacterium bovis infection and tuberculosis in cattle. Vet. J. 163:115-127.

Sambrook, J.; Fritscgh, E.F. and Meniates, T. (1989): Molecular cloning. A laboratory manual, 2nd Ed. ColdSpring Harbor, 141.

Soliman, Y.A.; Ghonim, M.; Nasr, E.A.; Mousse, I.; Ebiary ,E.A.; and Selim, S.A. (2004) Cloning and expression of recombinant MPB70 protein antigen from Mycobacterium bovis BCG for diagnosis of tuberculosis.Egypt J. Immunol. 2004; 11(2):21-9.

Stephen, V. G,; Roland, B.; Alain, B.; Thierry, G.; Karin, E. and Stewart, T.C. 1999.Identification of variable regions in the genomes of tubercle bacilli using bacterial

artificial chromosome arrays Molecular Microbiology 32(3): 643-655

Tripathi, K.; Tripathi, P.C.; Nema, S.; Shrivastava, A.K.; Dwiwedi, K. and Dhanvijay, A.K. 2014. Modified Petroff's Method: an Excellent Simplified Decontamination Technique in Comparison with Petroff's Method. Int. J. Recent Trends Sci. Technol. 10(3):461-464.

World Health Organization WHO. Laboratory services in TB controlpart: Microscopy. WHO/TB/98.258. Geneva: World Health Organization. 1998 